\title{
The combined process of pyrolysis and catalytic conversion from rice straw toward light olefin hydrocarbon with supported metal catalyst
}

\author{
Setiadi* $^{*}$ Jayusandi Mulya Sentosa and Joshua Jesse Karubaba \\ Department of Chemical Engineering, Faculty of Engineering, Universitas Indonesia, \\ Kampus Baru UI, Depok 16424, West Jawa, Indonesia
}

\begin{abstract}
Light olefins are one of the most common petrochemical raw materials produced using non-renewable natural resources. Nowadays, lignocellulosic biomass is a promising source of feedstock ingredients for the production of olefins by pyrolysis. This study, the process is developed by a combination of pyrolysis and catalytic cracking processes with operating temperature around $500^{\circ} \mathrm{C}$ and $\mathrm{N}_{2}$ flow rate around $150 \mathrm{ml} / \mathrm{min}$. The supported metal catalyst namely $\mathrm{La} / \mathrm{Al}_{2} \mathrm{O}_{3}$ and $\mathrm{Zn} / \mathrm{Al}_{2} \mathrm{O}_{3}$ made with the impregnation method are used as catalysts. The catalytic pyrolysis process was carried out in a fixed bed turbular reactor with electric furnace as the heat source. To comprehend the catalytic cracking with catalyst, the experiment was also performed in condition without catalyst so that it could be compared to pyrolysis process itself. The The output of pyrolysis is condensed by using cold absorption trap with aceton. FT-IR (Fourier Transform - Infrared) and GC-TCD (Gas Chromatography-Thermal Conductivity Detector) serve as analytical instrument in order to identify the presence and the quantity of light olefins group in bio-oil and bio-gas. In this method, there are several variations to be determine, there are type of catalyst and catalyst composition $(1 \%, 5 \%$, and $10 \%)$.
\end{abstract}

\section{Introduction}

Olefins and aromatic compounds are among the main products obtained by catalytic cracking of biomass pyrolysis vapors/bio-oil. These two hydrocarbon groups are the building blocks of petrochemical industry. Considering the wide range of applications of olefins and aromatics, it seems worthwhile to determine the factors which influence their production in bio-oil upgrading. Selectively, production of high yields of green aromatics and olefins through catalytic cracking of biomass pyrolysis vapor/bio-oil can be available alternative for production of these compounds from fossil fuel. This work is the first attempt to review the researches held in catalytic cracking of biomass pyrolysis vapors/bio-oil and bio-oil model compounds with the aim of defining the effects of the catalyst properties and reaction conditions which can change reaction selectivity in favor of aromatics and olefins [1].

Light olefins (i.e., ethylene, propylene and butylenes), which are the basic feedstocks for the petrochemical industry, are primarily produced through steam cracking and fluid catalytic cracking (FCC) using naphtha, light diesel and other petroleum products [2], but the production of olefins using biomass or biomassderived feedstocks is also possible [ $\underline{3}]$.

Catalytic conversion of biomass feedstocks into olefins was studied using HZSM-5 containing 6 wt.\% lanthanum. Biomass rich in cellulose or hemicellulose achieved higher olefins yield than the high-lignin feedstocks. Moderately increasing the medium acid sites of HZSM-5 via the incorporation of lanthanum effectively improved the selectivity and yield of olefins. Catalytic pyrolysis enhanced the production of olefins as comparing to pyrolysis. The results indicate that lignocellulosic biomass is a promising source of feedstock for the production of olefins [ 4 ].

The formation of light olefin compounds is commonly minor product in biomass pyrolysis. More likely, light olefins are only an intermediate during pyrolysis and susceptible converted into other compounds during the proceed of pyrolysis reaction, thus causing only a small amount of those olefins compounds could be obtained in the end of pyrolysis products [4]].

In this study, catalytic pyrolysis of biomass with $\mathrm{La}$ and $\mathrm{Zn}$-modified $\mathrm{Al}_{2} \mathrm{O}_{3}$ catalyst for selective light olefins production was carried out in a fixed bed reactor. There are several variations to be determined, there are type of catalyst and catalyst loading composition $(1 \%, 5 \%$, and $10 \%)$. The study may be helpful to deeply further the understanding of different parameters on biomass to light.

\section{Experimental}

Corresponding author: setiadi@che.ui.ac.id 


\subsection{Materials}

The type of biomass used as feed in this research is a rice straw. The samples of rice straw were originated from Pangandaran, West Jawa Indonesia. Rice straw was grinded and sieved into particle size of $400 \mu \mathrm{m}$. The samples were then dried in an oven at $60^{\circ} \mathrm{C}$ until attained a constant weight. All the samples were stored in sealed containers. The amount of samples used for each pyrolysis experiment was $2 \mathrm{~g}$. The sample of rice straw had main characteristic of the cellulose $(37.8 \%)$ []․

\subsection{Catalyst Impregnation Procedure}

Catalysts used for this experiment was consisted of two parts; the supporting catalyst and active side. Alumina $\left(\mathrm{Al}_{2} \mathrm{O}_{3}\right)$ was used as supporting catalyst meanwhile Lanthanum and Zinc metals were used as active site catalyst. The method for preparing the catalyst is called impregnation method. The supporting catalyst and the aqueous nitrate solution of active site precursors were mixed in beaker glass with each catalyst composition was $1 \%, 5 \%$, and $10 \% \mathrm{w} / \mathrm{w}$.

The mixture was dried by placing in a magnetic stirrer with equipped with heating pan at $80^{\circ} \mathrm{C}$ for two hours until the powder form formation. The calcination was carried out in electric furnace furnace at $300^{\circ} \mathrm{C}$ in 2 hours to remove the water content perfectly and subsequently calcined at $600^{\circ} \mathrm{C}$ for 2 hours to the formation of metal oxides form and to produce the strong interaction of dispersed metal oxides on the surface of $\mathrm{Al}_{2} \mathrm{O}_{3}$ catalyst support. The resulted catalyst preparations were denoted by $\mathrm{La} / \mathrm{Al}_{2} \mathrm{O}_{3}$ and $\mathrm{Zn} / \mathrm{Al}_{2} \mathrm{O}_{3}$. The amount of catalyst sample used for each pyrolysis experiment was 1 gram for each experiment.

\subsection{Pyrolysis procedure}

The combined process of pyrolysis and catalytic conversion was conducted in the operation of fixed bed reactor. The reactor was made from stainless-steel 316 tube with a diameter of $20 \mathrm{~mm}$. The configuration of fixed bed was composed of $2 \mathrm{~g}$ rice straw biomass in the upper part of bed and $1 \mathrm{~g}$ of catalyst in the lower one. Detail arrangement of reactor bed system is shown in fig.1.

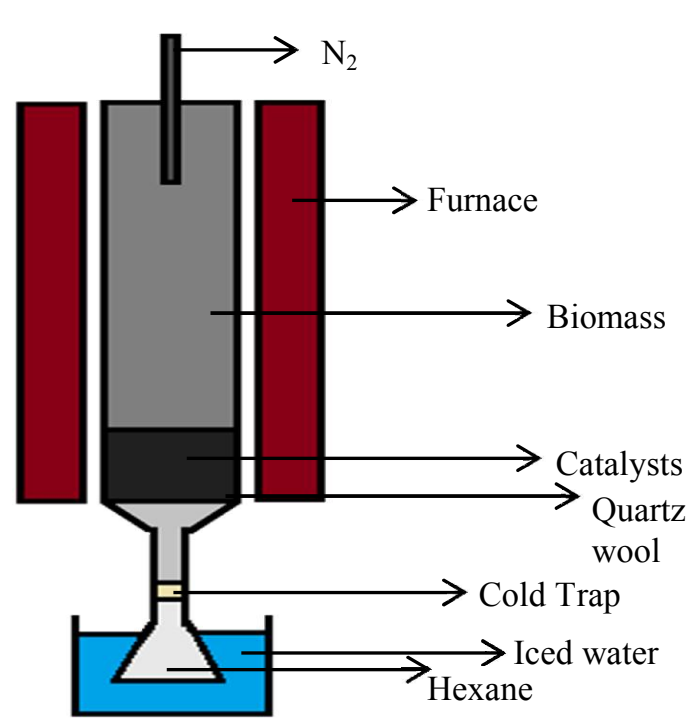

Fig. 1. Schematic diagram of experimental apparatus for biomass pyrolysis

The reactor was inserted into the electric furnace equipped with temperature control box with thermocouple injected in the middle position of furnace. The tip point of thermocouple was confirmed to contact to the wall of stainless steel reactor in order to fix the temperature set. The Nitrogen gas was introduced into the reactor through the top side and the operation of reactor pyrolysis was started by flowing the $\mathrm{N}_{2}$ gas flow rate fixed at $150 \mathrm{ml} / \mathrm{min}$ in atmospheric pressure. The gas flow was controlled by flow controlling valve and then measured the $\mathrm{N}_{2}$ flow in the effluent of reactor by bubble soap flowmeter. The function of $\mathrm{N}_{2}$ gas was an inert pyrolysis gas and to remove the possible air presence inside the reactor tube and to lead the reactor in the homogeneous temperature condition.

The operation of combined pyrolysis was previously to set up the furnace with the temperature control box at $500^{\circ} \mathrm{C}$. After the temperature reached, the fixed bed reactor was carefully fixed into the furnace and the $\mathrm{N}_{2}$ gas flowed into the reactor to carry out the gaseous product of pyrolysis at the bottom of reactor tube. Carries $\mathrm{N}_{2}$ and the products moved out and enter the absorption tube submerged in the cold ice-water bath kept in Dewar flask. The Liquid product could be perfectly condensed in this cold trap and the uncondensed gas was then flowing out from the cold absorption trap entering gas bag for collected samples. The condensation trapping condensation and gas absorption were shown in the figure 2. 


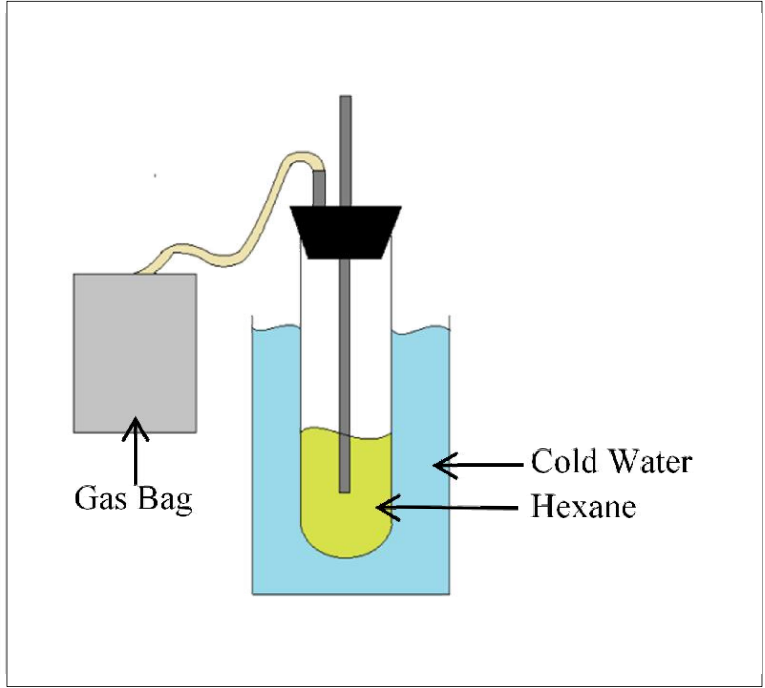

Fig. 2. Schematic diagram of experimental apparatus for condensation and gas absorption

The ice-water bath and hexane solvent for cold absorption trap was considered at same temperature measured $1{ }^{\circ} \mathrm{C}$ because those liquids were kept in the dewar flask. Non-condensable gas such as light olefin was stored in gas bags. Non-condensable gas was further analyzed with FT-IR (Fourier Transform Infrared) and GC-TCD (Gas-Chromatography Thermal Conductivity Detector) to identify the presence and of light olefin in gas.

\section{Result and discussion}

\subsection{Characterization of light olefin}

The objective of this study is primarily to obtain the light olefin compounds in non-condensable gas product. Light olefins should be in the form of gaseous product due to the condition of atmospheric pressure and the tiny amount comparing the $\mathrm{N}_{2}$ carrier gas. So, the olefins could be collected in the non-condensable gas after flowing the cold trap absorption. By using FT-IR, the presence of light olefin in the sample of gas could be detected and was shown in fig. 3. Light olefin is mainly consisted of light alkene, the presence could be attributed by the infrared spectrum in the range of wave number is $3010-3095 \mathrm{~cm}^{-1}, 1610-1680 \mathrm{~cm}^{-1}$, and $675-995$ $\mathrm{cm}^{-1}$ with the intensity for each wavelength is moderate, changeable, and strong []], which is shown in two figures $a$ and $b$ below.

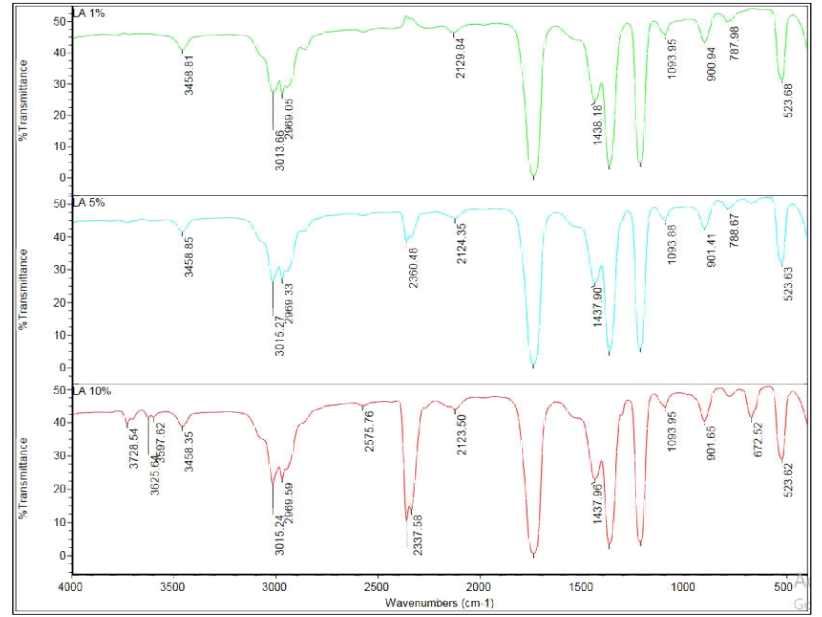

(a)

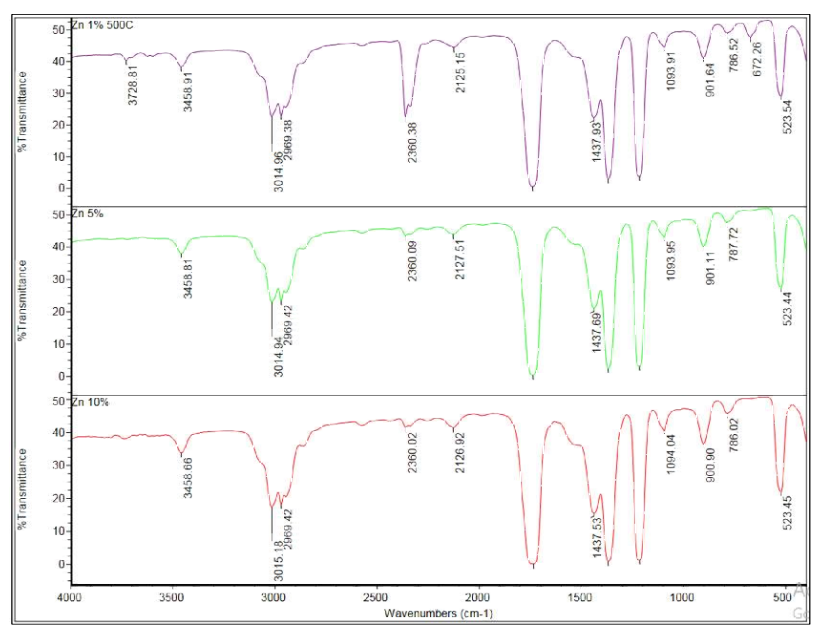

(b)

Fig. 3. FTIR spectrum of gas olefin product resulted from catalytic pyrolysis of rice straw (cellulose-rich biomass) using catalyst : (a) $\mathrm{La} / \mathrm{Al}_{2} \mathrm{O}_{3}$ (a) and (b) $\mathrm{Zn} / \mathrm{Al}_{2} \mathrm{O}_{3}$

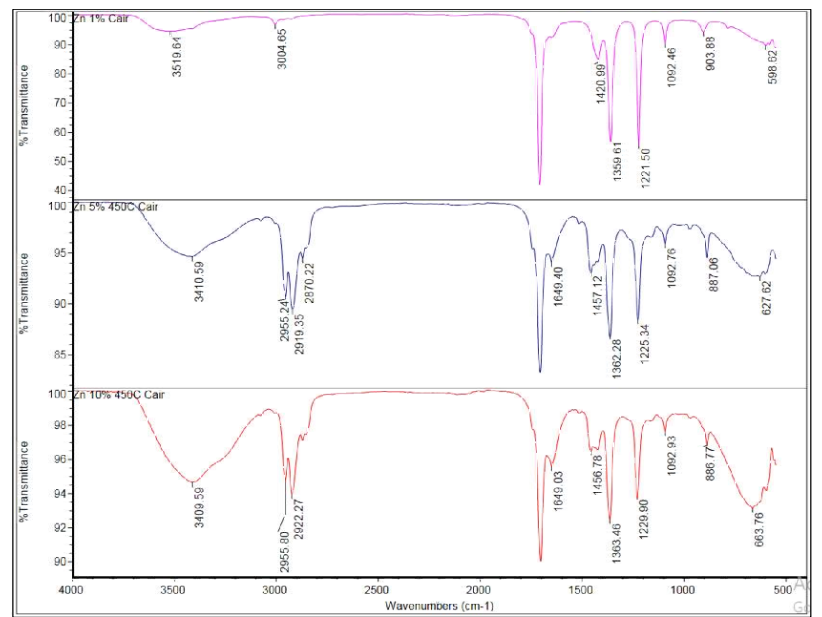

Fig. 4. FTIR spectrum of gas olefin product sample resulted from catalytic pyrolysis of lignin-rich biomass using catalyst $\mathrm{Zn} / \mathrm{Al}_{2} \mathrm{O}_{3}$ 
Figure 4 is clearly shown that FTIR spectrum of the sample gas with the using of lignin-rich biomass is enough different comparing to figure 3 . This result suggested that the amount of olefins produced from catalytic pyrolysis of cellulose-rich biomass is much higher than the olefins from that of lignin-rich one. So, the reaction mechanism for the formation of olefin compounds should be employed the feed stock from cellulose-rich biomass. To compare the result of olefin produced with using $\mathrm{La} / \mathrm{Al}_{2} \mathrm{O}_{3}$ and $\mathrm{Zn} / \mathrm{Al}_{2} \mathrm{O}_{3}$ catalyst, the following table (table 2) presents the results of the transmittance FT-IR spectrum data for light olefins peaks.

Table 2. Composition of light olefins from rice straw (cellulose-rich) pyrolysis

\begin{tabular}{ccccc}
\hline & & \multicolumn{3}{c}{ Light Olefins } \\
& & \multicolumn{3}{c}{ Transmittance (\%) } \\
\cline { 3 - 5 } Catalysts & Composition & $\begin{array}{c}3010- \\
3095 \\
\mathrm{~cm}^{-1}\end{array}$ & $\begin{array}{l}1610- \\
1680 \\
\mathrm{~cm}^{-1}\end{array}$ & $\begin{array}{c}675- \\
995 \\
\mathrm{~cm}^{-1}\end{array}$ \\
\hline & $1 \%$ & 27 & 44 & 42 \\
$\mathrm{La} / \mathrm{Al}_{2} \mathrm{O}_{3}$ & $5 \%$ & 25 & 42 & 42 \\
& $10 \%$ & 22 & 40 & 41 \\
\hline & $1 \%$ & 22 & 42 & 38 \\
$\mathrm{Zn} / \mathrm{Al}_{2} \mathrm{O}_{3}$ & $5 \%$ & 22 & 41 & 38 \\
& $10 \%$ & 18 & 40 & 34 \\
\hline
\end{tabular}

In general, the table 2 showed that the increasing of catalyst composition for $\mathrm{La} / \mathrm{Al}_{2} \mathrm{O}_{3}$ and $\mathrm{Zn} / \mathrm{Al}_{2} \mathrm{O}_{3}$ is lead to the decreasing of $\%$ transmittance for all ranges of wavenumber. But, it seems that the $\%$ transmittance of $\mathrm{La} / \mathrm{Al}_{2} \mathrm{O}_{3}$ catalyst with the wavenumber range 3010-3095 $\mathrm{cm}^{-1}$ is lead to significantly decreasing with the increasing of the composition than that of $\mathrm{Zn} / \mathrm{Al}_{2} \mathrm{O}_{3}$ catalyst. And also the \% transmittance of this range showed the significantly decrease as the increasing of $\mathrm{La} / \mathrm{Al}_{2} \mathrm{O}_{3}$ catalyst composition than that of other ranges. Indeed, the trend of \% transmittance should be inverse to the amount of light olefin containing in the samples.

To find how much yield of light olefin produced from pyrolysis process, the analytical instrument used was GC-TCD. The following table 2 presents the results of the GC-TCD analysis indicating light olefins content.
Table 2. Composition analysis of light olefins from rice straw (cellulose-rich) pyrolysis

\begin{tabular}{ccc}
\hline Catalysts & $\begin{array}{c}\text { Composition } \\
(\%)\end{array}$ & $\begin{array}{c}\text { Yield Light } \\
\text { Olefins (\%) }\end{array}$ \\
\hline $\mathrm{La} / \mathrm{Al}_{2} \mathrm{O}_{3}$ & 1 & 0.1 \\
& 5 & 0.26 \\
& 10 & 0.48 \\
\hline $\mathrm{Zn} / \mathrm{Al}_{2} \mathrm{O}_{3}$ & 1 & 0.36 \\
& 5 & 0.1 \\
& 10 & 0.08 \\
\hline
\end{tabular}

The largest presence of light olefin content in the test results using FT-IR is in the sample $\mathrm{Zn} / \mathrm{Al}_{2} \mathrm{O}_{3}$ with $\mathrm{Zn}$ content of $10 \%$ in wavelength $3010-3095 \mathrm{~cm}^{-1}$, but the largest yield of light olefins content in the results using the $\mathrm{GC}-\mathrm{TCD}$ is in the sample $\mathrm{La} / \mathrm{Al}_{2} \mathrm{O}_{3}$ with $\mathrm{La}$ content of $10 \%$. On FT-IR, that wavelength $3010-3095 \mathrm{~cm}^{-1}$ is for alkene, which means the presence of $10 \% \mathrm{Zn}$ sample does not all contain light olefins, but is still in the alkene category. In addition, the difference in transmittance in the $10 \% \mathrm{Zn}$ sample percent and La $10 \%$ did not differ significantly, $18 \%$ and $22 \%$, respectively.

\subsection{The effect of Lanthanum and Zinc metals as active site}

The effect of active side catalysts on the pyrolysis product (light olefins) content is shown in Table 2 . There is a slight difference in the transmittance percentage of the peak that indicating the presence of light olefins. The catalyst with zinc as an active site produces a smaller transmittance percentage.

In terms of active site composition against $\mathrm{Al}_{2} \mathrm{O}_{3}$ support, both active metals exhibit the same pattern. The greater the content of the active metal composition of the catalyst, the smaller the percent transmittance produced. Thus, the more detected light olefins content.

\subsection{The effect of catalyst on mass changes during pyrolysis of rice straw}

To investigate the effect of catalyst on changes in mass during pyrolysis of rice straw and coconut fibre, the mass of biomass and catalyst prior to pyrolysis are weighed, and byproducts after pyrolysis are also weighed so that the mass loss occurs during pyrolysis can be determined. 
Non-catalyzed biomass pyrolysis is also carried out in order to know effect of the catalyst in the mass shrinkage of biomass during pyrolysis process. The following graphic presents the results of the weighed biomass and catalyst before and after pyrolysis.

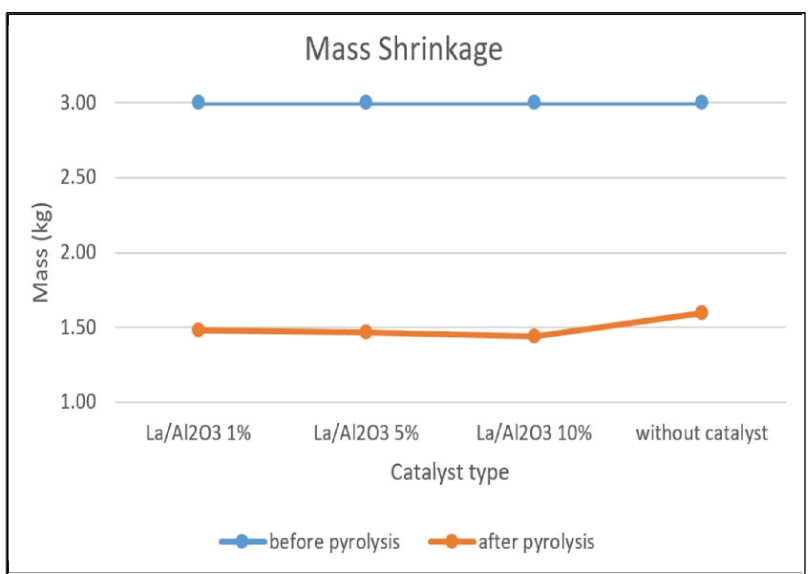

(a)

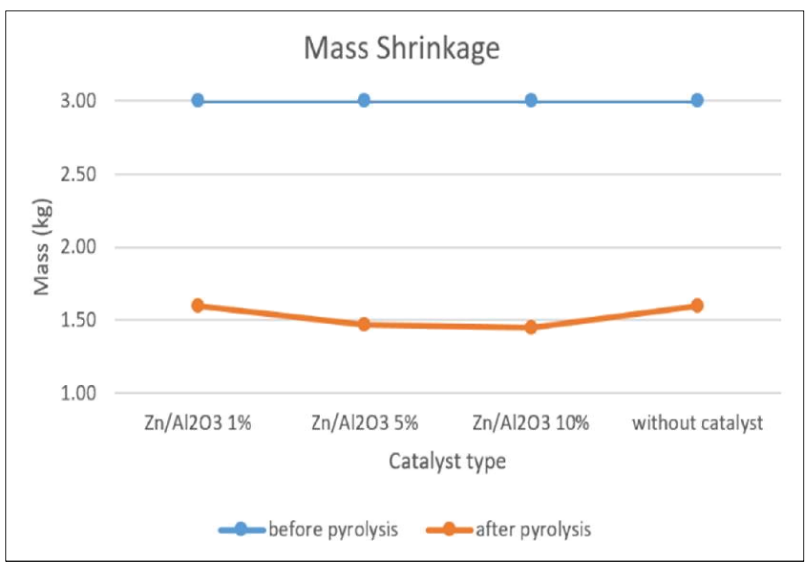

(b)

Fig. 5. Results of the weighed sample before and after pyrolysis for $\mathrm{La} / \mathrm{Al}_{2} \mathrm{O}_{3}$ (a) and $\mathrm{Zn} / \mathrm{Al}_{2} \mathrm{O}_{3}$ (b) catalysts type

Based on the above graph it can be seen that the composition of the catalyst metal active at the time after pyrolysis is very small or can be considered does not affect the shrinkage of mass that occurs during pyrolysis. The difference of mass after pyrolysis of each sample is very little due to the mass measurement done manually. The non-catalytic pyrolysis sample is also tested and the presence or absence of catalyst also does not affect the shrinkage of mass that occurs during pyrolysis. The interval mass after pyrolysis of each sample is around $1.53 \mathrm{~kg}-1.6 \mathrm{~kg}$.

\section{Conclusions}

Catalytic pyrolysis of raw rice straw were conducted in a fixed bed reactor with the absence and presence condition of impregnated catalysts $\mathrm{La} / \mathrm{Al}_{2} \mathrm{O}_{3}$ and $\mathrm{Zn} / \mathrm{Al}_{2} \mathrm{O}_{3}$. Pyrolysis experiments of rice straw were carried out in a fixed bed reactor with lanthanum and nickel metals as active catalyst to identify the presence and the yield of the light olefin.

The correlation tendency of \% transmittance of light olefin in the FT-IR analysis is significantly decreased along with the increasing the catalyst composition of $\mathrm{La} /$ $\mathrm{Al}_{2} \mathrm{O}_{3}$ in wavelength $3010-3095 \mathrm{~cm}^{-1}$. But for the sample $\mathrm{Zn} / \mathrm{Al}_{2} \mathrm{O}_{3}$ with $\mathrm{Zn}$ content of $10 \%$ with the FTIR of wavelength $3010-3095 \mathrm{~cm}^{-1}$ have lowest \% transmittance.

The yield of olefins tends to increase with the increasing of the catalyst composition of La component. The largest yield of light olefins content using the GCTCD analysis is achieved by the sample $\mathrm{La} / \mathrm{Al}_{2} \mathrm{O}_{3}$ with La content of $10 \%$

The performance of catalyst did not affect the mass decreasing during biomass thermal pyrolysis of rice straw by demonstrating the mass interval after pyrolysis at small intervals $(1.53 \mathrm{~kg}-1.6 \mathrm{~kg})$.

The authors would like to acknowledge the grant "Publikasi Internasional Terindeks untuk Tugas Akhir Mahasiswa" (PITTA) Universitas Indonesia with Grant number 2526/UN2.R3.1/HKP.05.00/2018 for the financial support for the research.

\section{References :}

1. Rezaei, P., Shafaghat, H.,, and Daud, W., Catalytic cracking of hydrocarbons over modified ZSM-5 zeolites to produce light olefins; a review. Appl. Catal. B 398. 2011. 1-17.

2. Rahimi, N., Karimzadeh, R., Production of green aromatics and olefins by catalytic cracking of oxygenate compounds derived from biomass pyrolysis: A review, Applied Catalysis A: General. 2013. 491-511.

3. Corma, A., et al., Chemical routes for the transformation of biomass into chemicals. Chem. Rev. 107. 2007. p. 2411-2502.

4. Huang, J., et al., Production of light olefins by catalytic conversion of lignocellulosic biomass with HZSM-5 zeolite impregnated with 6 wt.\% lanthanum. Bioresource Technology. 2012. p. 248255

5. Jung, S. H., Kang, B. S., and Kim, J. S., Production of bio-oil from rice straw and bamboo sawdust under various reaction conditions in a fast pyrolysis plant equipped with a fluidized bed and a char separation system. Journal of Analytical and Applied Pyrolysis. 2008. p. 240-247.

6. Skoog, D., Holler. F, and Crouch. S, Principles of instrumental analysis sixth edition. Thomson Higher Education, 2007. p. 461. 